\title{
The Use of Sweetened and Flavored Electronic Cigarettes Among Young People-A Growing Concern
}

\author{
An Expert Interview with Mary Cataletto
}

Department of Pediatrics, School of Medicine, Stony Brook University, Stony Brook, NY, US

DOI: https://doi.org/10.17925/USPRD.2019.4.1.12

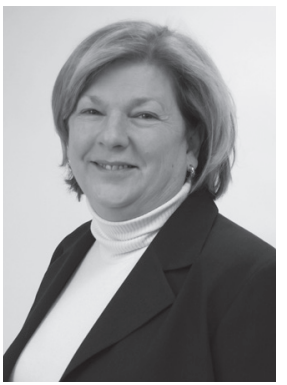

\section{Mary Cataletto}

Dr Cataletto is Professor of Clinical Pediatrics at the Stony Brook University School of Medicine, and a pediatric pulmonologist in practice at the New York University-Winthrop Hospital in New York. She is chair of the Pediatric Network of the American College of Chest Physicians and has presented on the impact of flavorings on the use of electronic cigarettes in American middle and high school students at their national meeting in San Antonio, TX, this year. Dr Cataletto is Editor in Chief of Pediatric Allergy, Immunology and Pulmonology.

\section{Keywords}

E-cigarettes, electronic cigarettes, smoking tobacco

Disclosures: Mary Cataletto has nothing to declare in relation to this article.

Review Process: This is an expert interview and, as such has not undergone the journal's standard peer review process.

Authorship: The named author meets the criteria of the International Committee of Medical Journal Editors for authorship for this manuscript, takes responsibility for the integrity of the work as a whole and has given final approval for the version to be published.

Received: December 3, 2018

Published Online: March 8, 2019

Citation: US Respiratory \& Pulmonary Diseases 2019;4(1):12-3

Corresponding Author: Mary Cataletto, 120 Mineola Boulevard, Suite 210, Mineola 11501

NY, USA. E: mary.cataletto@nyulangone.org

Support: No funding was received in the publication of this article.
- lectronic cigarettes (e-cigs) are often promoted as a safe alternative to conventional - tobacco-based cigarettes and as an aid to smoking cessation. The use of sweet and fruit-based flavorings, as well as targeted marketing strategies to attract teens, have resulted in a significant uptake in the use of these products in middle and high school students in the US. ${ }^{1}$ Potential customers can select from a vast array of flavoring options, and access information about e-cigs via social media and other online sources, as well as traditional marketing communication channels and face-to-face interaction with vape shop employees. The availability of sweetened and flavored brands has heightened their appeal for young people. However, despite substantial increases in e-cig consumption, little is known about the long-term health consequences of their use.

In an expert interview, Mary Cataletto discusses these issues, as well as a recent position statement of the Forum of International Respiratory Societies (FIRS) on the use of e-cigs in youths.

\section{Q. How prevalent is the use of electronic cigarettes in children and adolescents?}

Based on the 2017 National Youth Survey published by the US Food and Drug Administration, 2.1 million American middle and high school students had used e-cigs in the past 30 days. ${ }^{1} \mathrm{E}$-cig use has surpassed the use of conventional tobacco cigarettes in this age group and they are the most commonly used tobacco product in middle and high school students. ${ }^{2}$

\section{Q. What role do flavorings play in adolescent electronic cigarette use?}

The majority of youths, defined as between 12-17 years old, report that flavored e-cigs were their initiation into tobacco products, citing the availability of flavors and the ability to mix their favorite flavors as important factors. ${ }^{1-4}$ Adolescents who preferred more flavors used more e-cigs. Multimedia advertising promotes 'natural' flavors and aromas, so it is not surprising that flavors have also been reported as the main reason that teens continue to use them. ${ }^{5}$ There are thousands of flavors of e-cigs on the market (over 7,500 flavors estimated in 2014). ${ }^{6}$ The availability of multiple choices in flavors and the option to mix your own flavorings may help to 
maintain the novelty of e-cigs for teens and promote increased use. Fruit and sweet flavors are the most popular in youths. In a recent study by Kroemer at al., the addition of a sweet taste was shown to potentiate the reinforcing effects of nicotine?

\section{Q. What has been the adult experience with flavored electronic cigarettes as an aid to smoking cessation?}

Adult smokers are also influenced by flavorings, and the dual use of e-cigs and conventional tobacco is not uncommon. ${ }^{8}$ Many adults prefer menthol or tobacco flavor as they start to quit smoking, although sweet flavors become more popular as they continue to use e-cigs. ${ }^{3-4}$ It remains unclear whether e-cigs are an effective aid to smoking cessation.

\section{Q. Why is the use of sweetened electronic cigarettes among minors a controversial issue?}

There is no safe amount of nicotine exposure, and e-cigs are not a safe alternative to conventional tobacco cigarettes. ${ }^{9}$ Many youth believe that e-cigs are safer and more socially acceptable. ${ }^{10}$ While more research is needed, it appears that the sensitization to nicotine in e-cigs promotes conventional tobacco use as the nicotine cravings increase. Few users recognize that they are a likely gateway to conventional tobacco cigarettes. The brain continues to develop throughout adolescence and is particularly vulnerable to the addictive effects of nicotine. ${ }^{9}$ The adverse effects of e-cigs include those ascribed to nicotine itself, the contents of the aerosol (vapor), or to the temperature modification of the content. ${ }^{11}$

The sale of both e-cigs and conventional tobacco products are banned to minors in the USA, yet the 2017 US National Youth survey reported that approximately 2.1 million middle and high school students had used e-cigs in the past 30 days. ${ }^{1}$

\section{Q. What is being done to discourage the use of these products among minors?}

FIRS issued a position statement on e-cigs and electronic nicotine delivery systems use in youth. FIRS reflects a collaboration of professional organizations and respiratory experts; it is made up of nine international societies: the American College of Chest Physicians, American Thoracic
Society, Asian Pacific Society of Respirology, Asociación Latinoamericana de Tórax, the European Respiratory Society, the International Union Against Tuberculosis and Lung Disease, the Pan African Thoracic Society, the Global Initiative for Asthma and the Global Initiative for Chronic Obstructive Lung Disease.

They recommended:

'1. To protect youths, [electronic nicotine delivery systems] should be considered tobacco products and regulated as such, including taxation of electronic cigarettes and supplies. The addictive power of nicotine and its adverse effects in youths should not be underestimated.

2. Considering the susceptibility of the developing brain to nicotine addiction, the sale of electronic cigarettes to adolescents and young adults must be prohibited by all nations, and those bans must be enforced.

3. All forms of promotion must be regulated and advertising of electronic cigarettes in media that are accessible to youths should cease.

4. Because flavourings increase rates of youth initiation, they should be banned in electronic nicotine delivery products.

5. As electronic cigarette vapour exposes nonusers to nicotine and other harmful chemicals, use should be prohibited in indoor locations, public parks, and places where children and youths are present.

6. While their health risks are increasingly recognised, more research is needed to understand the physiological and deleterious effects of electronic cigarettes.

7. Routine surveillance and surveys concerning combustible and electronic cigarette use should be carried out in many settings to better understand the scope and health threat of tobacco products to youths in different countries and regions.' [sic $]^{12}$

In conclusion, it is clear that flavorings can influence initiation and contribute to the ongoing use of e-cigs. Nicotine is an addictive substance, and preteens and teens are particularly vulnerable. Legislation and enforcement of existing restrictions to targeted marketing to teens, sale to minors, as well as restriction of sweet and fruit flavorings, are important steps to protect the future health of our children. Additional studies are needed to further evaluate the safety and efficacy of e-cigs as an aid in smoking cessation. ${ }^{13} \square$
1. Wang TW, Gentzke A, Sharapova S, et al. Tobacco product use among middle and high school students - United States, 2011-2017. MMWR Morb Mortal Wkly Rep. 2018;67:629-33.

2. US Food \& Drug Administration. Youth tobacco use: National Youth Tobacco Survey. 2018. Available at: www.fda.gov/TobaccoProducts/PublicHealthEducation/ ProtectingKidsfromTobacco/ucm405173.htm (accessed January 22, 2019).

3. Huang LL, Baker HM, Meernik C, et al. Impact of non-menthol flavors in tobacco products on perceptions and use among yout young adults and adults: a systematic review. Tob Control. 2017;26:709-19.

4. Harrell MB, Weaver SR, Loukas A, et al. Flavored e-cigarette use: characterizing youth, young adult, and adult users. Prev Med Rep.
2017:5:33-40.

5. Centers for Disease Control and Prevention. Quick facts on the risks of e-cigarettes for kisd, teens, and young adults. 2018. Available at: www.cdc.gov/tobacco/basic_information/ecigarettes/Quick-Facts-on-the-Risks-of-E-cigarettes-for-KidsTeens-and-Young-Adults.html?s_cid=0sh-stu-home-slider-004\%20 (accessed January 22, 2019).

6. Zhu SH, Sun JY, Bonnevie E, et al. Four hundred and sixty brands of e-cigarettes and counting: implications for product regulation. Tob Control. 2014;23 (Suppl. 3):iii3-9.

7. Kroemer NB, Veldhuizen MG, Delvy R, et al. Sweet taste potentiates the reinforcing effects of e-cigarettes. Eur Neuropsychopharmacol. 2018;28:1089-102.

8. Kasza KA, Ambrose BK, Conway KP, et al. Tobacco-product use by adults and youths in the United States in 2013 and 2014. N Eng/ J
Med. 2017:376:342-53

9. Schraufnagel DE. Electronic cigarettes: vulnerability of youth. Pediatr Allergy Immunol Pulmonol. 2015;28:2-6.

10. Pepper JK, Ribisl KM, Brewer NT. Adolescents' interest in trying flavored e-cigarettes. Tob Control. 2016;25:ili62-6

11. Lodrup Carlsen KC, Skjerven HO, Carlsen KH. The toxicity of e-cigarettes and children's respiratory health. Paediatr Respir Rev. 2018;28:63-7.

12. Ferkol TW, Farber HJ, La Grutta S, et al. Electronic cigarette use in youths: a position statement of the Forum of International Respiratory Societies. Eur Respir J. 2018;51:pii:1800278.

13. Farsalinos K. Electronic cigarettes: an aid in smoking cessation, or a new health hazard? Ther Adv Respir Dis. 2018;12:1753465817744960. 